Check for updates

Cite this: RSC Adv., 2019, 9, 28857

Received 12th July 2019

Accepted 9th September 2019

DOI: $10.1039 / c 9 r a 05347 f$

rsc.li/rsc-advances

\section{Experimental investigation of shale oil recovery from Qianjiang core samples by the $\mathrm{CO}_{2}$ huff-n- puff EOR method}

\author{
Lei Li, (D) ab Chengwei Wang, ${ }^{\text {ab }}$ Dongsheng Li, ${ }^{\text {ab }}$ Jingang Fu, ${ }^{\text {ab }}$ Yuliang Su*ab \\ and Yuting LV (D) ${ }^{\mathrm{C}}$
}

$\mathrm{CO}_{2}$ Huff-n-Puff $(\mathrm{HnP})$ is an effective technique for enhancing oil recovery (EOR) that can be applied to shale oil reservoirs faced with poor natural productivity and low water injectivity. The main objective of this study is to investigate the interactions of $\mathrm{CO}_{2}$ and formation crude oil, and evaluate the $\mathrm{CO}_{2} \mathrm{HnP}$ performance in shale oil reservoirs in the Qianjiang depression in China. In this study, the variation rules of oil phase behavior, viscosity, saturation pressure, and swelling factor at different $\mathrm{CO}_{2}$ contents of 0 to $65 \%$ were studied. A series of $\mathrm{HnP}$ experiments were conducted. The factors affecting the oil recovery were discussed, and Nuclear Magnetic Resonance (NMR) tests were conducted on core samples at different stages of the $\mathrm{HnP}$ process. The results show that the injected $\mathrm{CO}_{2}$ can make an positive change in the crude oil phase behavior. The oil-gas two-phase region enlarges and the saturation pressure increases as more $\mathrm{CO}_{2}$ is dissolved in the formation oil, which is beneficial to oil production. The dissolution of $\mathrm{CO}_{2}$ in the oil phase increased the oil swelling degree by 1.492 times, and the viscosity decreased from 1.944 to $0.453 \mathrm{mPa}$ s. The $\mathrm{HnP}$ experimental results demonstrate that the soaking time should be determined based on the injection pressure. Miscible conditions is a viable option for $\mathrm{CO}_{2}$ $\mathrm{HnP}$ as $10 \%$ more oil can be produced using miscible $\mathrm{HnP}$ and save more than half of the soaking time. The results illustrate that fracture is the most important factor affecting oil recovery, and the performance of $\mathrm{HnP}$ EOR on core samples with fractures is almost $25 \%$ better than those without fractures. However, the core matrix permeability has an almost negligible effect on the performance of $\mathrm{CO}_{2} \mathrm{HnP}$. The NMR tests show that the oil recovered in the first cycle was dominated by macropores and mesopores, followed by small pores. In the latter $\mathrm{HnP}$ cycles, the oil in small pores and micropores becomes the main oil-producing area. This study may provide a better understanding of the $\mathrm{CO}_{2} \mathrm{HnP}$ enhanced recovery strategy for shale reservoirs.

\section{Introduction}

$\mathrm{CO}_{2}$ is safe, reliable, and has a wide range of sources, and is the most promising gas source for enhanced oil recovery technology. ${ }^{1-4} \mathrm{CO}_{2}$ has good solubility in crude oil, and the solubility of $\mathrm{CO}_{2}$ increases with the increase of pressure. ${ }^{5,6}$ Under reservoir conditions, $\mathrm{CO}_{2}$ can dissolve in crude oil, expanding crude oil volume, reducing the oil viscosity and oil-gas interfacial tension, and increasing crude oil mobility. ${ }^{7,8}$ All these mechanisms provide favorable conditions for crude oil production. ${ }^{9}$ At the same time, $\mathrm{CO}_{2}$ is a common greenhouse gas. The public

${ }^{a}$ Key Laboratory of Unconventional Oil \& Gas Development (China University of Petroleum (East China)), Ministry of Education, Qingdao, China. E-mail: suyuliang@upc.edu.cn; Tel: +86-15224450387

${ }^{b}$ School of Petroleum Engineering, China University of Petroleum (East China), Qingdao, China

${ }^{c}$ College of Mechanical and Electronic Engineering, Shandong University of Science and Technology, Qingdao, China has paid more and more attention to the greenhouse effect nowadays. In addition to studying $\mathrm{CO}_{2}$ emissions reduction, the way to make effective use of $\mathrm{CO}_{2}$ also becomes a research hotspot. ${ }^{10,11} \mathrm{CO}_{2}$ injection technology can effectively develop lowpermeability oil and gas resources. Meanwhile, it can alleviate the greenhouse effect to a certain extent. ${ }^{12}$ There are two types of $\mathrm{CO}_{2}$ injection which are $\mathrm{CO}_{2}$ flooding and $\mathrm{CO}_{2}$ huff-n-puff (HnP). During the $\mathrm{CO}_{2}$ flooding mode, $\mathrm{CO}_{2}$ is injected through one injection well, and oil and gas will be produced from one production well. In the hydraulic fractured shale reservoirs, the injected $\mathrm{CO}_{2}$ will break through from the injection well to the production well along the fractures or high permeability channels in reservoirs. Whereas, $\mathrm{CO}_{2} \mathrm{HnP}$ uses one well as both injection well and production well to avoid gas break through. There are three stages during this process: gas injection stage, well soaking stage, and production stage. After the process, the oil under the control of the well will be produced. ${ }^{\mathbf{1 3 , 1 4}}$ Three main characteristics make $\mathrm{CO}_{2} \mathrm{HnP}$ an efficient and feasible EOR technology. First, it's economically 
feasible and relatively easier to inject $\mathrm{CO}_{2}$ to shale reservoirs to keep the reservoir pressure high as compared to most of the other high viscosity injection fluids such as water or polymer. ${ }^{15}$ With high injectivity, the oil swept volume improved, resulting in more residual oil that can be driven. ${ }^{\mathbf{1 6}}$ Second, the injected $\mathrm{CO}_{2}$ improved oil displacement efficiency by dissolving into the shale oil and influencing the oil/gas phase equilibrium during the soaking period. Third, during the production stage, a dissolved gas drive is formed when pressure drops. Combined with the function of oil-gas interfacial tension reduction, more oil can be produced. ${ }^{17,18}$ The HnP schedule such as the work time for the three stages or the gas injection rate and injection pressure can be adjusted based on the properties of reservoirs. Thus, $\mathrm{CO}_{2} \mathrm{HnP}$ has the advantages of strong pertinence, short cycle, and fast capital recovery. ${ }^{\mathbf{1 9}}$

$\mathrm{CO}_{2} \mathrm{HnP}$ was first applied in heavy oil production. In the mid-1960s in China, the laboratory experiments were conducted in Daqing and Shengli Oilfields, respectively. In the mid-1990s, Daqing oilfield, Jiangsu oilfield, Jilin oilfield, Zhongyuan oilfield in China all carried out some pilot tests. ${ }^{20,21}$ However, the development progress of this technology is relatively slow due to the shortage of $\mathrm{CO}_{2}$ resources and the prominent gas channeling contradiction in China. In the United States, the $\mathrm{CO}_{2}$ $\mathrm{HnP}$ test was carried out in light oil reservoirs. Bretagne (1985) successfully conducted the $\mathrm{CO}_{2} \mathrm{HnP}$ test in Shoemaker Oilfield in shallow light-oil-depleted reservoirs. ${ }^{22}$ Their results showed that crude oil production was increased by 2-3 times, and the water content was reduced by more than $90 \%$. Monger et al. (1988) conducted 14 field tests and combined them with laboratory experiments to study the stimulation effect of $\mathrm{CO}_{2}$ in light oil reservoirs. ${ }^{23}$ They proved that $\mathrm{CO}_{2}$ could increase the residual oil production after water flooding. Since 1990, the United States Appalachian Basin started $\mathrm{CO}_{2} \mathrm{HnP}$ production, which lasted for 5 years, and implemented a total of $390 \mathrm{HnP}$ operations in 240 wells, with a total oil increase of $12476 \mathrm{t.}^{24} \mathrm{It}$ is concluded that the change of water/oil relative permeability by $\mathrm{CO}_{2} \mathrm{HnP}$ is the main mechanism of the reservoir stimulation. Torabi and Asghari (2010) conducted a laboratory study to examine the performance and efficiency of $\mathrm{CO}_{2} \mathrm{HnP}$ in light-oil fractured porous media. ${ }^{25}$ The results showed that $\mathrm{CO}_{2} \mathrm{HnP}$ technology significantly improved the recovery, and it recovered more than $95 \%$ of the oil from the fracture-matrix experimental model saturated with normal decane when the $\mathrm{CO}_{2} \mathrm{HnP}$ was conducted at 13.34 MPa. They also announced that the effect of core permeability was less pronounced when $\mathrm{CO}_{2}$ was injection at miscible conditions.

Recent years, $\mathrm{CO}_{2} \mathrm{HnP}$ method has been applied to enhance unconventional oil recovery in light oil and tight reservoirs. ${ }^{26-28}$ Song et al. (2013) compared water and $\mathrm{CO}_{2}$ injection experiments on cores of Bakken tight formation, and obtained that the degree of $\mathrm{CO}_{2}$ recovery under near-miscible and miscible conditions was higher than that under water flooding. ${ }^{29}$ Gamadi et al. (2014) did experiments to study the cyclic $\mathrm{CO}_{2}$ injection in shale oil EOR using mineral oil and cores from Mancos and Eagle Ford. ${ }^{30}$ The laboratory results indicated that cyclic $\mathrm{CO}_{2}$ injection improved recovery of shale oil cores from $33 \%$ to $85 \%$ depending on the shale core type and the other operating parameters. Li and Sheng measured the efficiency of shale oil recovery through laboratory experiments and numerical simulation of using methane $\mathrm{HnP} .{ }^{31}$ Yu et al. (2016) further explored the influences of soaking time and consumption time on fracture-matrix shale reservoirs in huff and puff experiments using $\mathrm{N}_{2} \cdot{ }^{32}$ Li et al. (2019) conducted experiments comparing the effect of $\mathrm{N}_{2}$ and $\mathrm{CO}_{2}$ on EOR performance, verifying the great potential of $\mathrm{CO}_{2}$ in improving shale oil recovery. ${ }^{33}$ Other researchers use commercial software such as CMG and Eclipse to simulate the process of $\mathrm{CO}_{2} \mathrm{HnP}$, and investigated the influences of parameters including pressure, injection rate, gas diffusivity, soaking time, and fractures on the efficiency of $\mathrm{HnP}$ EOR. ${ }^{34-41}$ Sheng (2017) reviewed and discussed previous experiments and simulations on gas injection recovery in shale reservoirs. ${ }^{42}$ He concludes that gas injection in shale reservoirs is more practical and effective than other EOR methods. The simulation results reflect the $\mathrm{CO}_{2} \mathrm{HnP}$ performance to some extent. However, the simulation method includes lots of assumption, which cannot represent the real core characteristics, such as core heterogeneity, pore size distribution, organic matter properties, and so on. Experiment work on core scale samples have indicated the great potential of $\mathrm{CO}_{2} \mathrm{HnP}$ in the recovery of shale oil. However, it is seen that core samples used in the experiments are purely matrix without presence of natural fractures. The experiments of core samples with presence of natural fractures will be more practical significance to evaluate oil production potential from shales. Also, in all the above study, the oil properties changes such as oil swelling properties, phase behavior due to the addition of $\mathrm{CO}_{2}$ are not well discussed. The underlying mechanisms of $\mathrm{CO}_{2} \mathrm{HnP}$ cannot be well understood without the analysis of the reaction of $\mathrm{CO}_{2}$ and the target shale oil.

At present, the application of $\mathrm{CO}_{2}$ huff-n-puff technology in shale reservoir is still in the stage of laboratory research and field test. This technology has many advantages than other kinds of EOR method. (1) Cost effective production is the main challenge given the current economic situation of steady low oil prices. $\mathrm{CO}_{2} \mathrm{HnP}$ has low injection cost and wide sources of the injection gas. (2) $\mathrm{CO}_{2} \mathrm{HnP}$ can be applied to reservoirs with different permeability, especially to shale reservoirs with poor response to water injection and severe water sensitivity. (3) The implementation of technology is simple. (4) The oil development effect and economic benefit are good and the risk is small. At the same time, there are some challenges when applying this technology. The EOR mechanisms are complex, leading to the difficulty of controlling the EOR effect. Another problem is that it's difficult to accurately predict the development effect as so many factors influencing the implement process. Thus, fully understanding the mechanisms of enhanced oil recovery and the influences of different injection parameters of this process are significant.

In this paper, we investigate the changes of formation oil phase behavior, saturation pressure, swelling factor, viscosity deduction when adding different percentage of $\mathrm{CO}_{2}$ to understand the main interactions of injected $\mathrm{CO}_{2}$ and formation crude oil. Then we conducted $\mathrm{CO}_{2} \mathrm{HnP}$ tests on shale core samples from Qianjiang depression in China. 
Matrix cores with different permeability and cores with natural fractures were all applied to evaluate the shale oil production potential. The influence of key factors (gas injection pressure, soaking time, permeability, miscible condition) on the performance of $\mathrm{CO}_{2}$ huff and puff were discussed.

\section{Interactions of $\mathrm{CO}_{2}$ and formation crude oil}

\subsection{Physical properties of $\mathrm{CO}_{2}$}

$\mathrm{CO}_{2}$ exists in four forms: gas phase, liquid phase, solid phase and supercritical phase under different pressure and temperature conditions as shown in Fig. 1. The point at which the liquid and gas phase are in equilibrium is called the critical point. The critical temperature of $\mathrm{CO}_{2}$ is about $31.2{ }^{\circ} \mathrm{C}$, and the critical pressure is about 7.38 MPa. When the temperature and pressure are higher than the critical point, $\mathrm{CO}_{2}$ is in supercritical condition. At this condition, the gasliquid interface disappeared, and its density is close to the density of a fluid. However, its viscosity and diffusion coefficient is still close to ordinary gas. The density of gas-phase $\mathrm{CO}_{2}$ can be calculated by eqn (1). In different phase states, the density of $\mathrm{CO}_{2}$ varies greatly, as shown in Fig. 2. The $\mathrm{CO}_{2}$ density decreases as the system temperature increases or the system pressure decreases.

At a certain temperature, the liquid $\mathrm{CO}_{2}$ density is not significantly affected by pressure. As the temperature rises, $\mathrm{CO}_{2}$

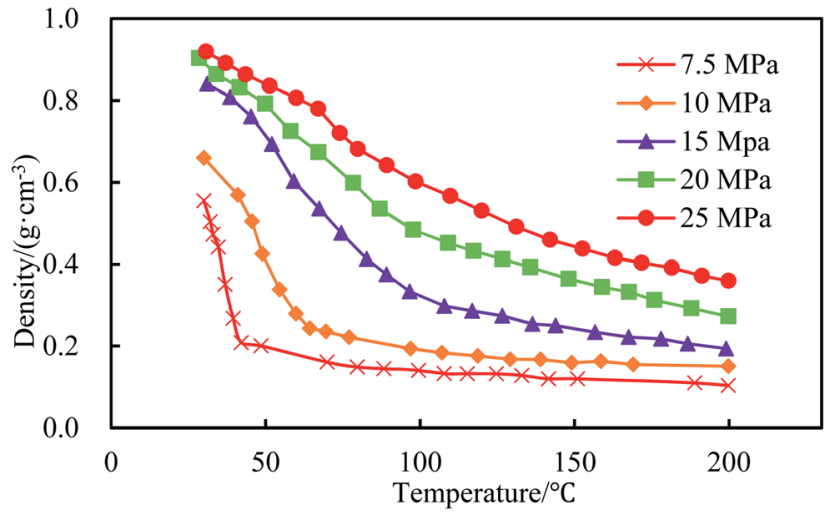

Fig. 2 Density distribution curves under different pressures of $\mathrm{CO}_{2}$.

changes from liquid phase to gas phase, leading to density decreases. When the system is in a supercritical state, the change of $\mathrm{CO}_{2}$ density is greatly affected by system temperature and pressure.

$$
\rho_{\mathrm{CO}_{2}}=\frac{p M_{\mathrm{CO}_{2}}}{Z R T}
$$

\subsection{The effect of $\mathrm{CO}_{2}$ on formation oil phase behavior}

The shale oil used in this paper is obtained from Qianjiang depression. The initial reservoir pressure is $18.62 \mathrm{MPa}$, and the

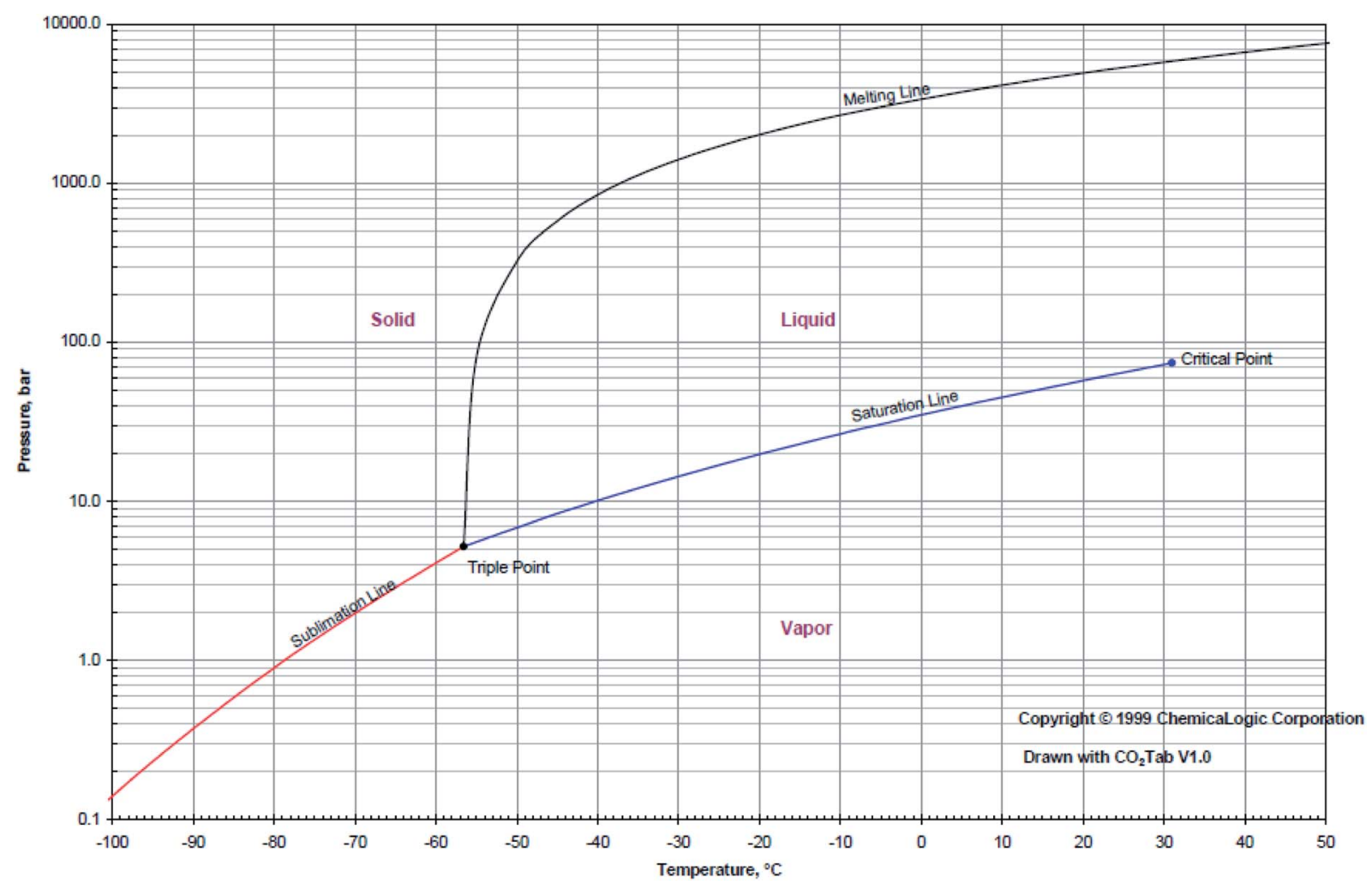

Fig. $1 \mathrm{CO}_{2} P-T$ phase behavior diagram (Copyright @1999 ChemicaLogic Corporation). 
Table 1 Shale oil composition of separator oil, separator gas, and formation crude oil

\begin{tabular}{llll}
\hline Oil composition & $\begin{array}{l}\text { Separator } \\
\text { oil }\end{array}$ & $\begin{array}{l}\text { Separator } \\
\text { gas }\end{array}$ & $\begin{array}{l}\text { Formation crude } \\
\text { oil }\end{array}$ \\
\hline $\mathrm{N}_{2}$ & 0 & 3.262 & 1.59 \\
$\mathrm{CO}_{2}$ & 0 & 0.621 & 0.3 \\
$\mathrm{CH}_{4}$ & 0.18 & 47.211 & 23.11 \\
$\mathrm{C}_{2} \mathrm{H}_{6}$ & 0.22 & 13.139 & 6.52 \\
$\mathrm{C}_{3} \mathrm{H}_{8}$ & 1.61 & 19.569 & 10.36 \\
$\mathrm{IC} 4$ & 2.77 & 2.773 & 1.73 \\
$\mathrm{NC} 4$ & 1.72 & 7.392 & 4.48 \\
IC5 & 2.82 & 1.819 & 2.27 \\
$\mathrm{NC5}$ & 3.38 & 2.028 & 2.72 \\
FC6 & 8.27 & 1.422 & 4.93 \\
FC7 & 4.92 & 0.571 & 2.8 \\
FC8 & 5.87 & 0.193 & 2.95 \\
FC9 & 5.21 & 0 & 2.51 \\
FC10 & 4.06 & 0 & 2.08 \\
C11 to C41 & 58.97 & 0 & 31.65 \\
& & &
\end{tabular}

temperature is $69.9{ }^{\circ} \mathrm{C}$. The separator oil, separator gas, and formation crude oil compositions are presented in Table 1 . The Peng-Robinson equation of state is used to calculate the phase behavior of $\mathrm{CO}_{2}$ and crude oil system as shown in the following equations.

$$
\begin{gathered}
P=\frac{R T}{v-b}-\frac{\alpha(T)}{v(v+b)+b v-b^{2}} \\
\alpha(T)=\alpha(T) \alpha_{\mathrm{c}} \\
\alpha_{\mathrm{c}}=\frac{0.45724 R^{2} T_{\mathrm{c}}^{2}}{p_{\mathrm{c}}} \\
\alpha(T)=\left[1+k\left(1-T_{\mathrm{r}}^{0.5}\right)\right]^{2} \\
k=0.37464+1.54226 \omega-0.26992 \omega^{2}
\end{gathered}
$$

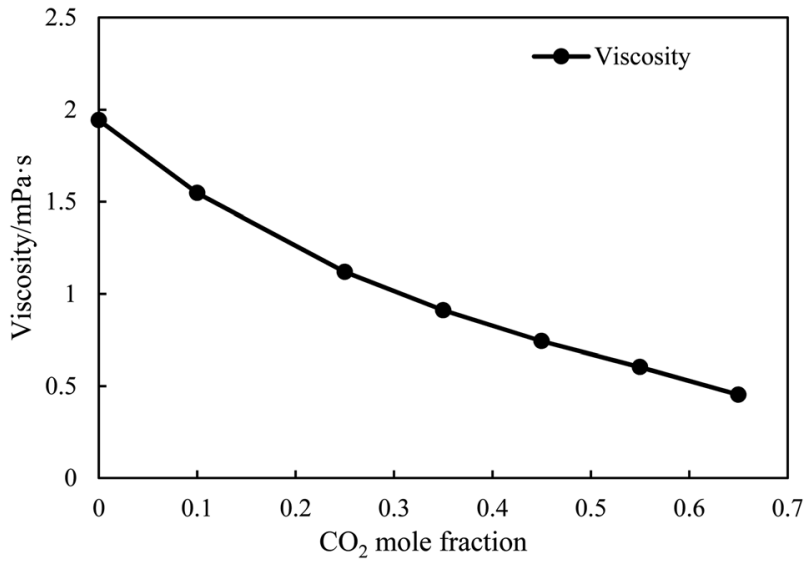

Fig. 4 The changes of formation oil viscosity with different $\mathrm{CO}_{2}$ mole fractions at reservoir condition $\left(P=18.62 \mathrm{MPa}, T=69.9^{\circ} \mathrm{C}\right)$.

$$
b=\frac{0.0778 R T_{\mathrm{c}}}{p_{\mathrm{c}}}
$$

where $v$ is the gas molar volume, $\mathrm{m}^{3} \mathrm{~mol}^{-1} ; T_{\mathrm{r}}$ is the relative temperature, $T_{\mathrm{c}}$ is the critical temperature, $p_{\mathrm{c}}$ is the critical pressure, $\mathrm{MPa}$; $\omega$ is the eccentric factor.

In the process of $\mathrm{CO}_{2} \mathrm{HnP}$, the injected $\mathrm{CO}_{2}$ will affect the formation oil phase behavior. The EOS Peng-Robinson model was used to calculate the phase behavior of $\mathrm{CO}_{2}$ and formation crude oil system under different $\mathrm{CO}_{2}$ mole fraction, as shown in Fig. 3. It shows that with the increase of $\mathrm{CO}_{2}$ content in the oil phase, the oil-gas two-phase zone enclosed by the bubble point line and the dew point line increases continuously. The critical temperature of the system gradually decreases, and the critical pressure of the system gradually increases. It also indicates that during $\mathrm{CO}_{2} \mathrm{HnP}$, the bubble point pressure of crude oil increases after $\mathrm{CO}_{2}$ is injected into the formation, which is beneficial to conduct solution gas drive and contribute to oil production.

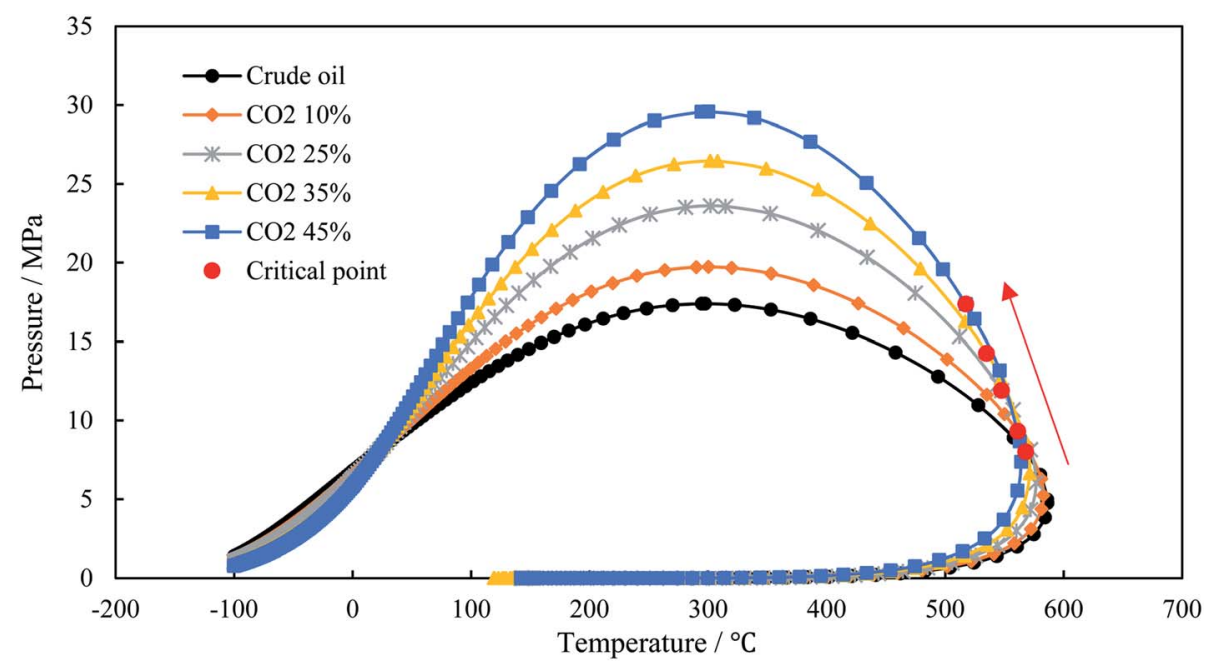

Fig. 3 Phase behavior of crude oil and $\mathrm{CO}_{2}$ system at different $\mathrm{CO}_{2}$ mole fractions. 


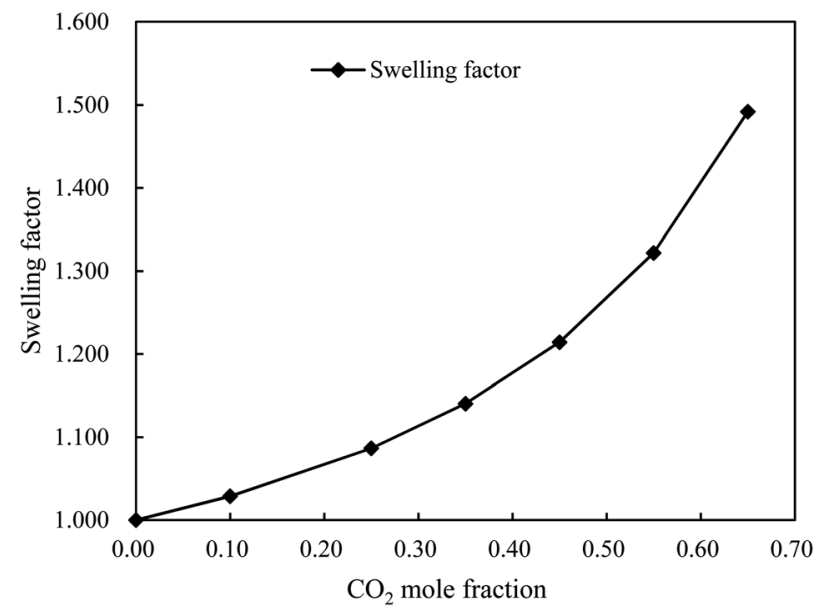

Fig. 5 The changes of formation oil swelling factor at different $\mathrm{CO}_{2}$ mole fractions.

\subsection{The effect of $\mathrm{CO}_{2}$ on formation oil properties}

During the gas $\mathrm{HnP}$, when $\mathrm{CO}_{2}$ is injected into the formation, some of the $\mathrm{CO}_{2}$ will dissolve into the crude oil. The solubility of $\mathrm{CO}_{2}$ is related to temperature, pressure, salinity, and molecular weight of crude oil. The $\mathrm{CO}_{2}$ solubility decreases with the increase of salinity and the increase of crude oil molecular weight. The dissolved $\mathrm{CO}_{2}$ will expand the volume of crude oil, changing the crude oil viscosity and density, and reducing

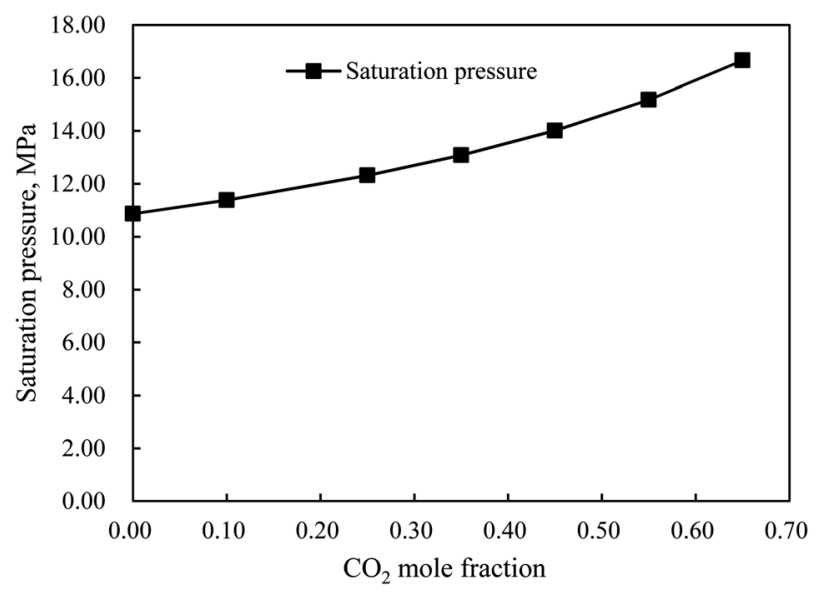

Fig. 6 The changes of formation oil saturation pressure at different $\mathrm{CO}_{2}$ mole fractions. interfacial tension. When $\mathrm{CO}_{2}$ is dissolved in light oil, the volume is generally increased by 1.4-1.6 times; when $\mathrm{CO}_{2}$ is dissolved in heavy oil, the volume is generally increased by 1.051.32 times. Fig. 4-6 shows the changes of oil viscosity, swelling factor, saturation pressure with different $\mathrm{CO}_{2}$ mole fraction. It can be seen that with the $\mathrm{CO}_{2}$ content increases from 0 to $65 \mathrm{~mol} \%$, the oil viscosity declines from $1.94 \mathrm{mPa} s$ to 0.453 $\mathrm{mPa}$ s, the swelling factor increases to 1.492 , and the saturation pressure increases from $10.86 \mathrm{MPa}$ to $16.66 \mathrm{MPa}$. It illustrates that $\mathrm{CO}_{2}$ will achieve obvious swelling and viscosity reduction effect when it is injected into a reservoir and fully contacted with formation crude oil.

\section{3. $\mathrm{CO}_{2}$ huff-n-puff experiments}

\subsection{Experimental materials}

The core samples used in this study were cut from the outcrop of Qianjiang formation in China. A total of 3 cores were used in this study as presented in Fig. 7. We determine the porosity and permeability of the core samples using the pulse decay method by helium injection. The properties of the core samples are shown in Table 2. There are some micro-fractures in Core \#2. Thus its total permeability is $2.67 \times 10^{-3} \mu \mathrm{m}^{2}$, which is much higher than the permeability of the others. The oil used in the core saturation was the separated oil as shown in Table 1 with a density of $0.8545 \mathrm{~g} \mathrm{~cm}^{-3}$ and a viscosity of $3.49 \mathrm{cP}$ at the temperature of $20{ }^{\circ} \mathrm{C}$. Distilled water is used in the experiment to pressurize the syringe pump. The $\mathrm{CO}_{2}$ used in this study was from Qingdao Tianyuan company, China, with a purity of $99.9 \%$.

\subsection{Experimental procedures}

As shown in experiment schematic Fig. 8 and 9, the main instruments and equipment used in this experiment are $\mathrm{CO}_{2}$ cylinder, core container, type II core container, pressure sensor, syringe pump, ISCO pump, accumulator, vacuum pump, and oven.

The HnP test contained two parts, including core sample saturation with crude oil and gas HnP process. During the core saturation oil process, the core samples were cleaned with toluene and dried in the oven at $70{ }^{\circ} \mathrm{C}$ for $36 \mathrm{~h}$. Then the core samples were weighed and recorded as $w_{\mathrm{d}}$. After that, the core samples were put into the type II core container and vacuumed for $48 \mathrm{~h}$ to completely remove the air in the pores. Crude oil was

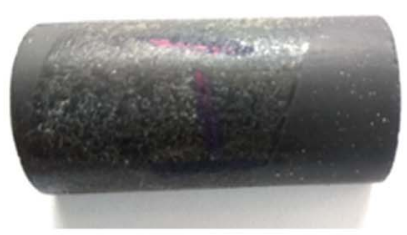

(a) Core \#1

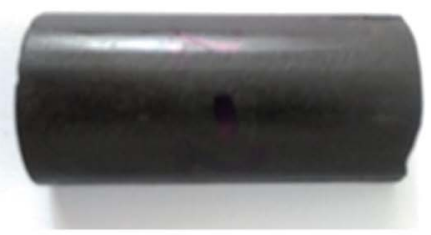

(b) Core \#2

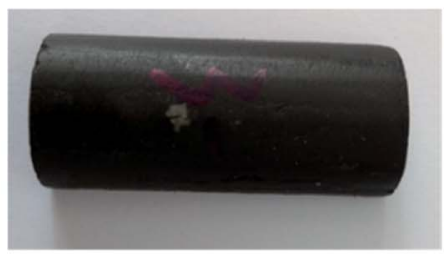

(c) Core \#3

Fig. 7 Qianjiang formation outcrop core samples used in this study. 
Table 2 Core samples specifications

\begin{tabular}{lllllll}
\hline Core no. & $\begin{array}{l}\text { Length, } \\
\mathrm{m}\end{array}$ & $\begin{array}{l}\text { Diameter, } \\
\mathrm{m}\end{array}$ & $\begin{array}{l}\text { Porosity, } \\
\%\end{array}$ & $\begin{array}{l}\text { Effective porosity, } \\
\%\end{array}$ & $\begin{array}{l}\text { Matrix permeability, } \\
\left(10^{-3} \mu \mathrm{m}^{2}\right)\end{array}$ & $\begin{array}{l}\text { Total permeability, } \\
\left(10^{-3} \mu \mathrm{m}^{2}\right)\end{array}$ \\
\hline Core \#1 & 4.85 & 2.49 & 14.5 & 12.75 & 0.034 & 0.034 \\
Core \#2 & 5 & 2.4 & 10.72 & 10.13 & 0.011 & 2.67 \\
Core \#3 & 5 & 3.7 & 8.6 & 7.78 & 0.008 & 0.008
\end{tabular}

then injected into the core container and a pressure of $30 \mathrm{MPa}$ was maintained for one month to fully saturate the core samples. After these processes, the core samples were removed out and weighed as the saturated core $w_{\mathrm{s}}$.

After saturation, the core sample was put into the $\mathrm{HnP}$ vessel. Before starting the experiment, we first test the whole system by injecting $\mathrm{N}_{2}$ at a pressure of $20 \%$ higher than the designed experiment pressure and make sure no leakage during all the process. The flow chart of experimental equipment for $\mathrm{HnP}$ is shown in Fig. 9. The main procedures of $\mathrm{CO}_{2} \mathrm{HnP}$ include injection stage, soaking stage, and production stage. During the injection stage, the core sample was put into the type II container and $\mathrm{CO}_{2}$ gas was injected into the container to the designed pressure $(8 \mathrm{MPa} / 13 \mathrm{MPa} / 20 \mathrm{MPa})$. All valves were then closed during soaking period $(0.5 \mathrm{~h} / 3 \mathrm{~h} / 8 \mathrm{~h})$ to allow the injected $\mathrm{CO}_{2}$ to fully contact and reacted with the oil in core sample. During the production process, the pressure of container was released to atmosphere pressure. The core sample was weighed again and record as $w_{\mathrm{i}}$ when the core mass is no longer changed (usually waiting for 6 hours). After these stages, the first HnP cycle is completed. Repeat the above steps to conduct more HnP cycles based upon experiment requirements.

The experimental operation schedule is shown in Table 3. The oil recovery factor of cycle $\mathrm{i}\left(R_{\mathrm{i}}\right)$ can be calculated using eqn (8).

$$
R_{\mathrm{i}}=\frac{w_{\mathrm{s}}-w_{\mathrm{i}}}{w_{\mathrm{s}}-w_{\mathrm{d}}} \times 100 \%
$$

\subsection{Nuclear Magnetic Resonance (NMR) experiment}

The NMR experiment in this study is to explore the sequence of oil recovered in different pore sizes during the HnP process. In this experiment, five different statuses, including the saturated core, the core after the first, second, fourth, and sixth cycles, were selected to do the NMR analysis. In the generated NMR spectrum, T2 relaxation time has a good correspondence with the shale pore radius. Longer $\mathrm{T} 2$ relaxation time results in a larger pore radius. Generally, pores with relaxation time distributed within the range of $0-1 \mathrm{~ms}$ are regarded as micropores. Pores with relaxation time within the range of 1-10 ms, 10-100 ms, and greater than $100 \mathrm{~ms}$ are small pores, mesopores, and macropores. ${ }^{43}$ By comparing and analyzing the NMR $\mathrm{T} 2$ spectrum of residual oil distribution at the end of different $\mathrm{CO}_{2} \mathrm{HnP}$ cycle, the oil production and contribution of different pore sizes to the enhanced oil recovery can be obtained. ${ }^{\mathbf{4}}$

\section{Results and discussion}

\subsection{The effect of different injection pressure on oil recovery}

$\mathrm{CO}_{2} \mathrm{HnP}$ tests were conducted on three core samples with the same soaking time of $0.5 \mathrm{~h}$ and different injection pressures, which were $8 \mathrm{MPa}, 13 \mathrm{MPa}$, and $20 \mathrm{MPa}$. Each test has $6 \mathrm{HnP}$ cycles. As shown in Fig. 10, $\mathrm{CO}_{2} \mathrm{HnP}$ is an effective method to enhance oil recovery in shale cores. After six HnP cycles, the oil recovery factor for Core $\# 1$ at injection pressures of 8,13 , and $20 \mathrm{MPa}$ are $25.9 \%, 47.1 \%$, and $55.4 \%$, respectively. The results also indicate that all these three core samples with different permeability have a similar trend of performance. The oil recovery factor increased as the injection pressure increased. The oil recovered amount in one cycle during $\mathrm{CO}_{2} \mathrm{HnP}$ process is presented in Fig. 11. The oil recovery factor obtained in the first HnP cycle is the largest. In the subsequent HnP cycles, the recovered oil increment in each cycle gradually decreases and tends to be stable. For Core \#2, the oil recovery differences for

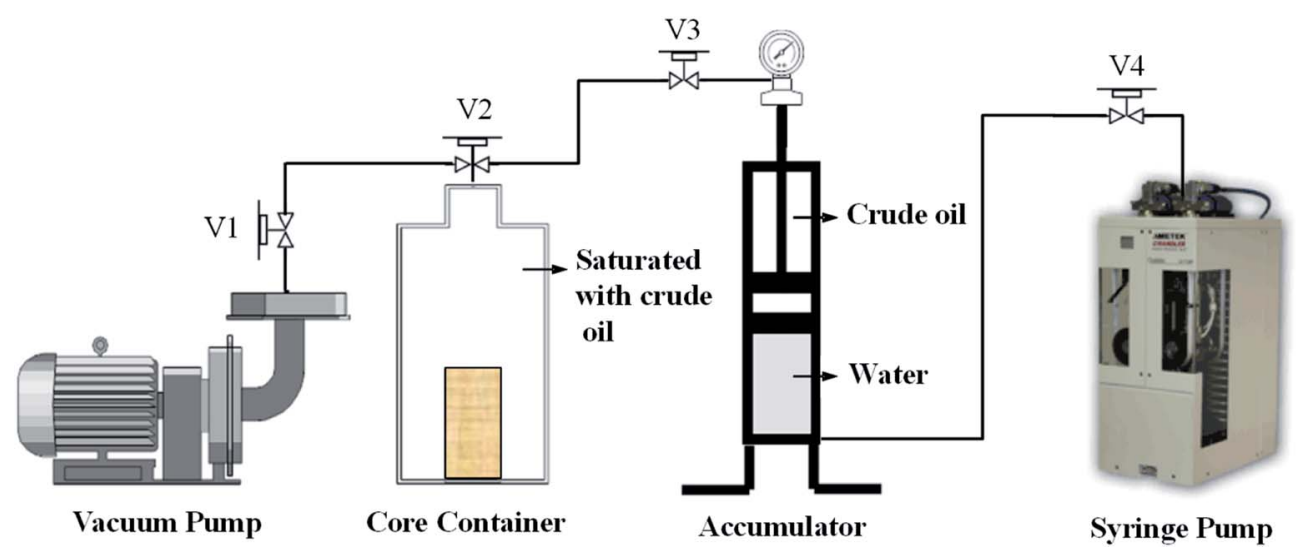

Fig. 8 Schematic diagram of saturated oil experimental equipment. 


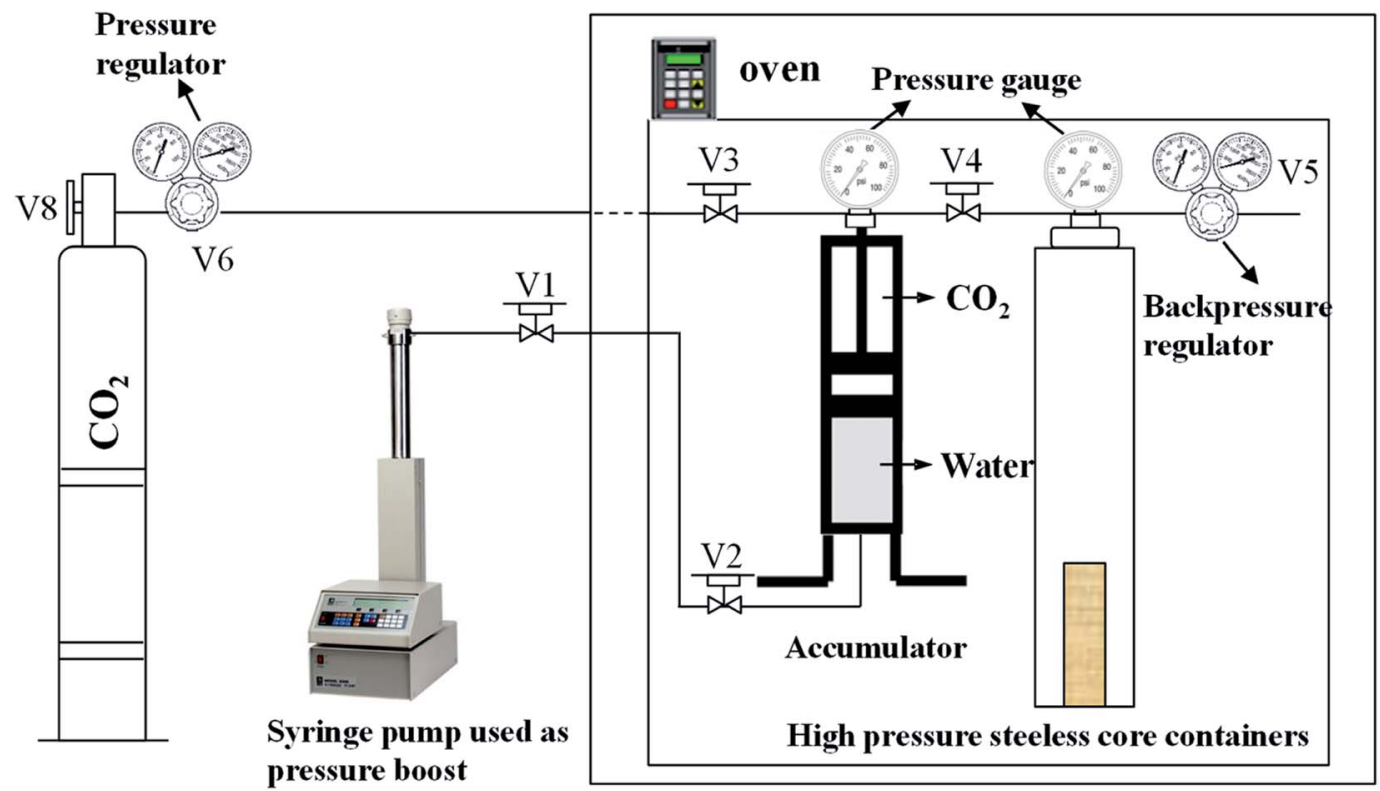

Fig. 9 Schematic of the set up for the $\mathrm{CO}_{2} \mathrm{HnP}$ experiments.

three different injection pressures comes from the first three cycles, especially the first cycle. For Core \#1 and Core \#3, comparing the performance of injection pressures of $8 \mathrm{MPa}$ and $13 \mathrm{MPa}$, the oil recovered in each cycle at low injection pressure is lower than that at higher injection pressure. However, for the oil recovery of injection pressures $13 \mathrm{MPa}$ and $20 \mathrm{MPa}$, both exceeding the MMP of $\mathrm{CO}_{2}$ and oil, the main difference of the oil recovery comes from the first three cycles. From the fourth cycle, there is not much difference in the amount of oil recovered in one cycle. This shows that under immiscible condition, the oil recovery increases as the injection pressure increases, and after it reaches the MMP, the effect of injection pressure is not as significant as before. It also indicates that the injection pressure should be higher than MMP of the $\mathrm{CO}_{2}$ and formation oil system to maintain a good EOR performance.

\subsection{The effect of soaking time on oil recovery}

It takes some time for $\mathrm{CO}_{2}$ to dissolve into the crude oil after injected into the reservoir. Therefore, a period of shut-in time called soaking time is required after gas injection. Too short the soaking time will lead to insufficient contact between $\mathrm{CO}_{2}$ and crude oil, which will affect the crude oil swelling. However, if the soaking time is too long, $\mathrm{CO}_{2}$ may diffuse to the reservoir boundary, affecting the energy storage near the area of production well and causing a waste of time. In this section, Core \#3 is used to explore the influence of different soaking time on shale oil recovery.

The variation of recovery factor with different soaking times of $0.5 \mathrm{~h}, 3 \mathrm{~h}$, and $8 \mathrm{~h}$ under 3 different injection pressures are presented in Fig. 12. These three cases yield the similar trends that the longer the soaking time, the higher the oil recovery factor. The characteristics of low porosity and low permeability of shale cores determine that the substituted crude oil diffuses and flows slowly in the matrix. Comparing with the three figures, we can find that when the injection pressure is low (8 $\mathrm{MPa}$ ), the oil recovery factor increases as the soaking time increases. However, when the injection pressure becomes higher, the soaking time does not have a significant effect on oil production. It can be found that, when the injection pressure is $20 \mathrm{MPa}$, the oil produced in different cycles with a soaking time of $3 \mathrm{~h}$ is gradually close to that with a soaking time of $8 \mathrm{~h}$. The advantages of long soaking time will gradually lose at high pressure. Therefore, there exists an optimal soaking time in the $\mathrm{CO}_{2} \mathrm{HnP}$ EOR method.

\subsection{The effect of core permeability and fractures on oil recovery}

In these three core samples, Core \#2, with a permeability of 2.67 $\times 10^{-3} \mu \mathrm{m}^{2}$, has fractures along the longitudinal section which can be observed from the cross-section of the core. There are no fractures on Core \#1 and Core \#3. The permeability of Core \#1 is $0.034 \times 10^{-3} \mu \mathrm{m}^{2}$, and the permeability of Core \#3 is $0.008 \times$ $10^{-3} \mu \mathrm{m}^{2}$. The performances of $\mathrm{CO}_{2} \mathrm{HnP}$ after six cycles at different injection pressures are shown in Fig. 13. The core with

Table 3 Experimental operation schedule

\begin{tabular}{llll} 
Cores & Injection pressure/MPa & Soaking time/h & Production time/h \\
\hline Core \#1 & 8 & 0.5 & 1 \\
Core \#2 & & 3 & \\
Core \#3 & & 8 & \\
Core $\# 1$ & 13 & 0.5 & \\
Core \#2 & & 3 & \\
Core \#3 & & 8 & \\
Core \#1 & 20 & 0.5 & \\
Core \#2 & & 3 & \\
Core \#3 & 8 &
\end{tabular}


fractures has an oil recovery more than $17.8 \%$ higher than that of matrix cores at injection pressure of $8 \mathrm{MPa}$. With the injection pressure increases, the advantage of fractures become
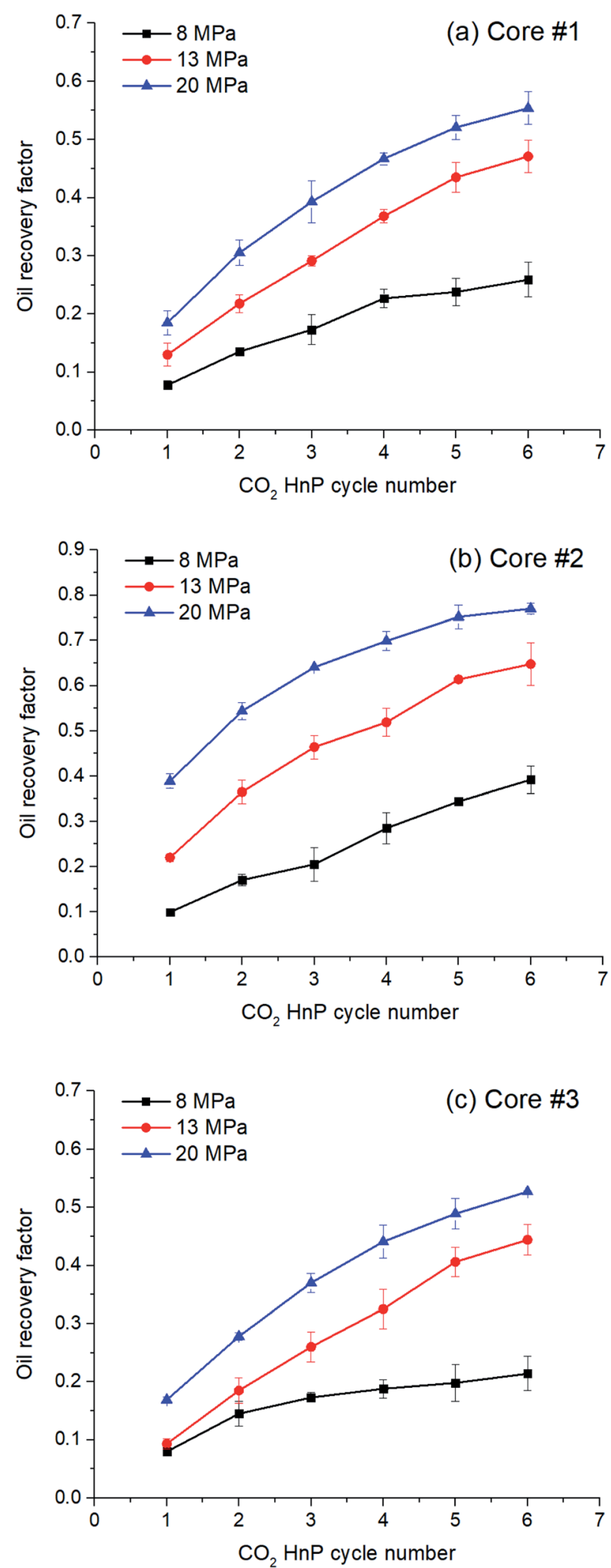

Fig. 10 Oil recovery factor curves of $\mathrm{CO}_{2} \mathrm{HnP}$ at different injection pressures. more obvious. When the injection pressures are $13 \mathrm{MPa}$ and $20 \mathrm{MPa}$, the oil recovery factors are more than $20.4 \%$ and $24.3 \%$ than that without fractures. It illustrates that fractures play an
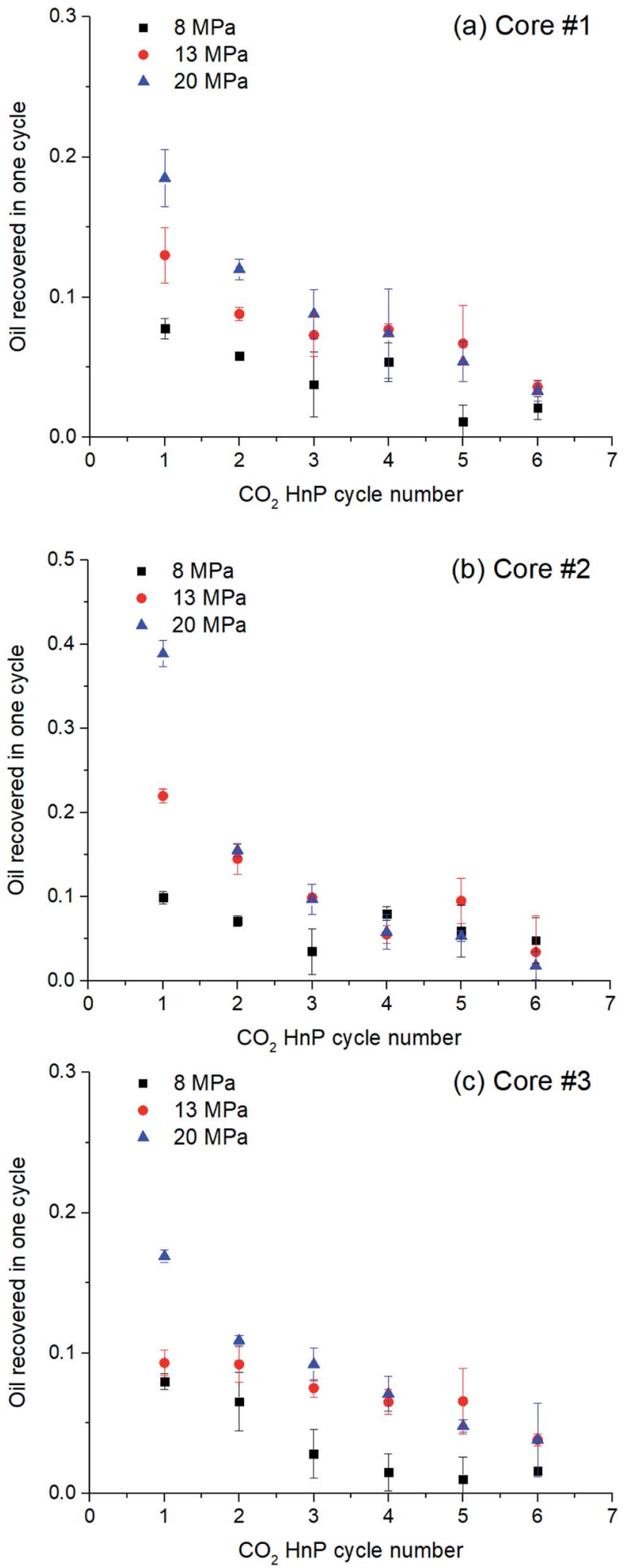

Fig. 11 Oil recovered amount in one cycle during $\mathrm{CO}_{2} \mathrm{HnP}$ at different injection pressures. 
important role in enhancing recovery efficiency during $\mathrm{CO}_{2} \mathrm{HnP}$ process. For the two cores without fractures, the difference of oil recovery is not significant (less than 3\%) as the increase of the
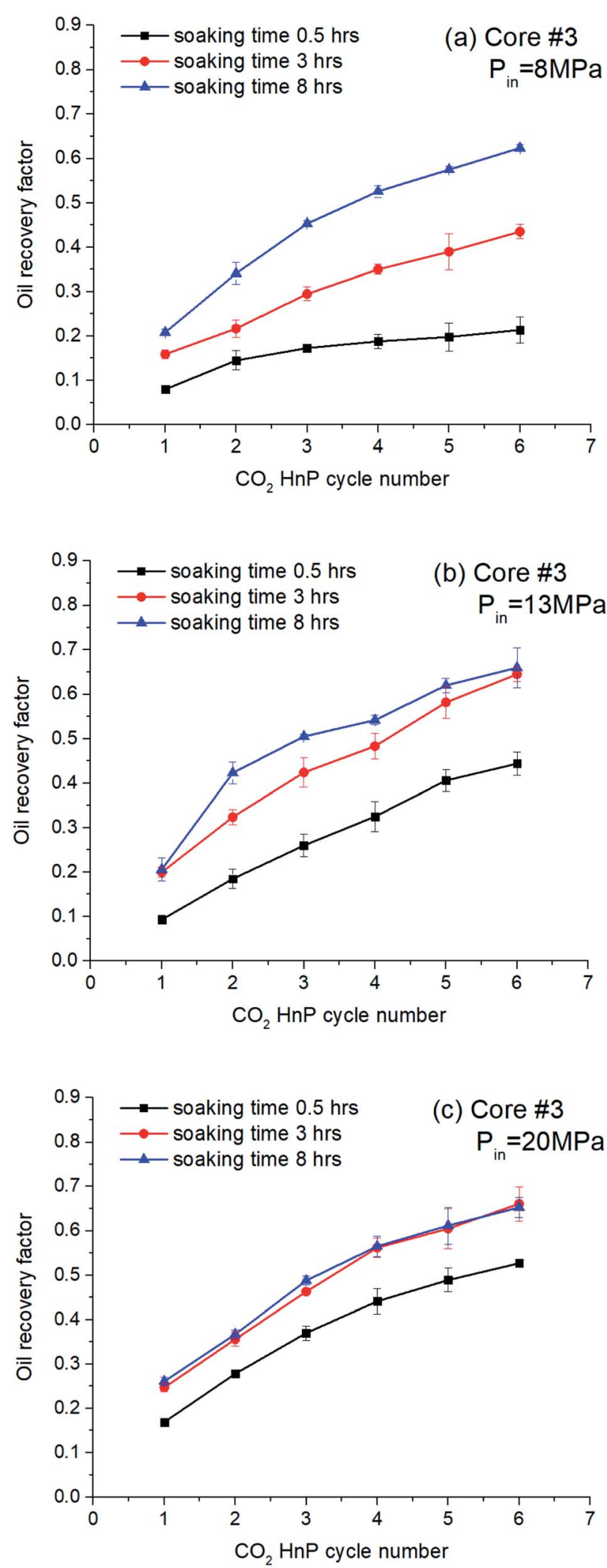

Fig. 12 Soaking time effect on the $\mathrm{CO}_{2} \mathrm{HnP}$ performance with different pressure (Core \#3).

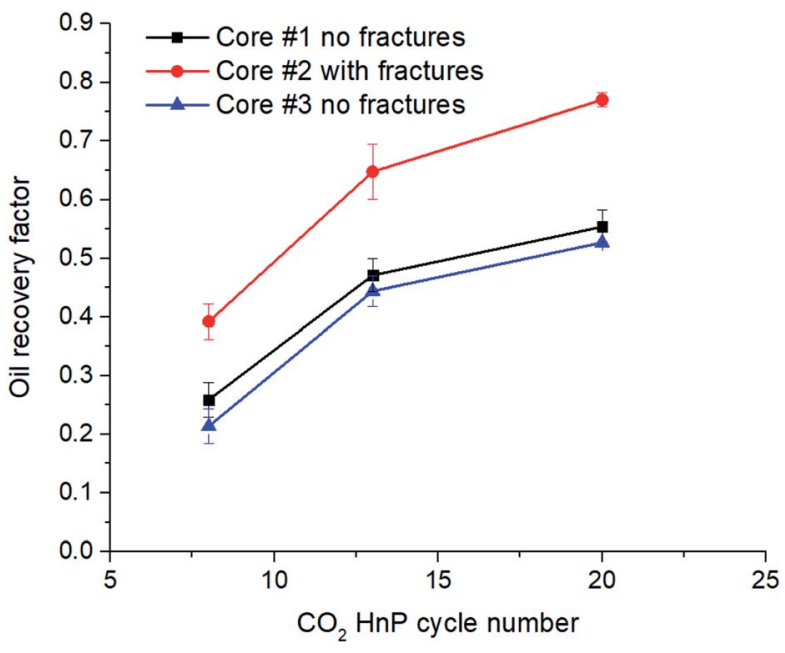

Fig. 13 Matrix permeability and fracture effect on $\mathrm{CO}_{2}$ huff-n-puff performance at different injection pressures (six $\mathrm{HnP}$ cycles, soaking time $=0.5 \mathrm{~h}$ ).

matrix permeability. Fig. 14 presents the oil recovery factor at different HnP cycles at an injection pressure of $20 \mathrm{MPa}$ for these three core samples. It indicates that the oil recovery factor difference comes from the first HnP cycle. In the subsequent cycle, fractures do not contribute much to the oil recovery. Thus, it indicates that the oil in fractures has small flow resistance due to the high fracture conductivity. During the $\mathrm{CO}_{2} \mathrm{HnP}$ process, the oil in the fractures with low resistance will be produced first. Then the oil in the pores will flow into the fracture and be displaced out in the following HnP cycles.

\subsection{The effect of miscible condition on oil recovery}

The measured minimum miscible pressure of $\mathrm{CO}_{2}$ and crude oil was 12.75 MPa. The tests were conducted on Core \#1 at a soaking time of $3 \mathrm{~h}$ Fig. 15 shows the final oil recovery factor of Core

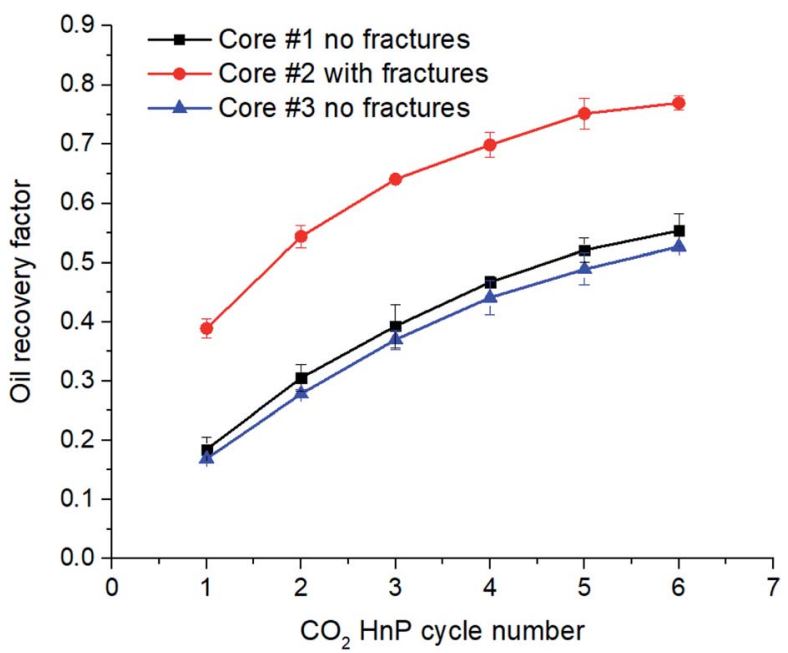

Fig. 14 Matrix permeability and fracture effect on $\mathrm{CO}_{2}$ huff-n-puff performance at different $\mathrm{HnP}$ cycle $(P=20 \mathrm{MPa}$, soaking time $=0.5 \mathrm{~h})$. 
\#1 after $6 \mathrm{HnP}$ cycles under different operating pressures. By observing the changes of oil recovery factor under different conditions including immiscible (8 $\mathrm{MPa})$, near miscible (13 $\mathrm{MPa}$ ) and miscible (20 MPa), we can obtain that the oil recovery factors change significantly when the operating conditions vary from immiscible to miscible. The oil recovery factor was $29.7 \%$ in the first $\mathrm{HnP}$ cycle when $\mathrm{CO}_{2}$ injected at $13 \mathrm{MPa}$, and $63.7 \%$ of the oil was produced at the end of $6 \mathrm{HnP}$ cycles. However, when the injection pressure was $8 \mathrm{MPa}$, the maximum oil recovery factor achieved for each cycle is much lower than that near miscible condition. Table 4 presents the oil recovered in each of the HnP cycle under three different conditions. It indicates that the increase rate of oil recovered gradually slowed down in the subsequent cycle compared with the previous one. In the last three cycles, the recovery rate gradually decreased. It can be seen that when the HnP cycle increases under miscible condition, the high pressure gradually loses its advantage. Thus, miscible condition is favorable for enhancing oil recovery than immiscible conditions. During the $\mathrm{CO}_{2} \mathrm{HnP}$ process, there are three ways of material exchange exist: the injected $\mathrm{CO}_{2}$ will selectively take up components from the oil phase (vaporizing mechanism), the oil may take up components from the gas phase (condensing mechanism), or both oil and gas may take up components from the other phase (combined vaporizing and condensing drive). ${ }^{45}$ In the immiscible condition, both gas phase and oil phase are present, the gas will have a higher mobility than the oil phase, and this may possibly lead to a gas breakthrough, which means the major part of the production will consist of gas. While, under miscible condition, only one phase is presented in the reservoir, which is advantageous for oil production. ${ }^{45}$

\subsection{The microscopic oil production process with NMR tests}

By comparing and analyzing the NMR T2 spectrum of microscopic residual oil distribution at the end of different $\mathrm{CO}_{2} \mathrm{HnP}$

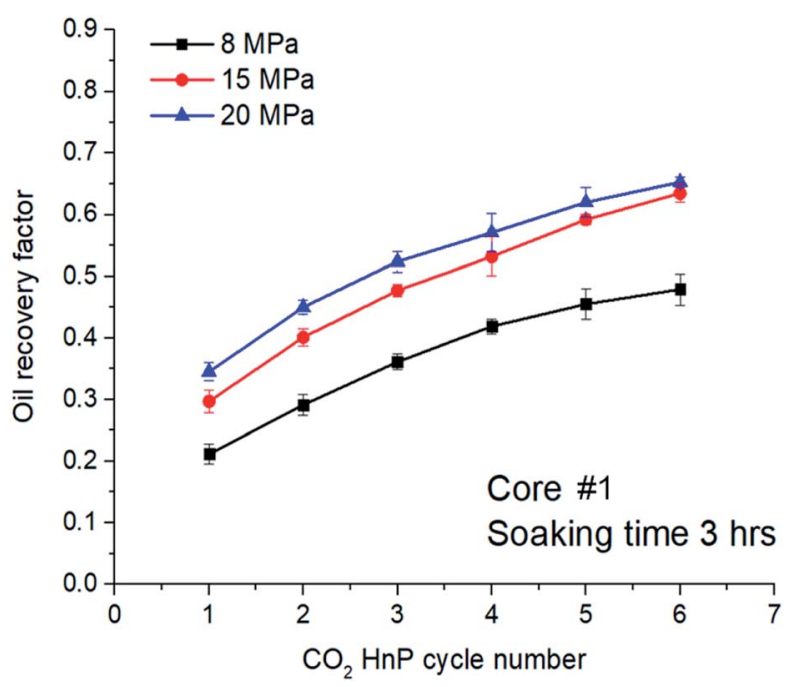

Fig. 15 Effect of different miscible conditions on oil recovery factor (Core \#1).
Table 4 The increment of oil recovery factor on each injection cycles (Core \#1)

\begin{tabular}{lllr}
\hline & \multicolumn{3}{l}{ Injection pressure } \\
\cline { 2 - 4 } $\begin{array}{l}\text { HnP cycle } \\
\text { number }\end{array}$ & $8 \mathrm{MPa}$ & $13 \mathrm{MPa}$ & $20 \mathrm{MPa}$ \\
\hline Cycle 1 & 21.2 & 29.7 & 34.5 \\
Cycle 2 & 7.9 & 10.4 & 10.5 \\
Cycle 3 & 7.0 & 7.6 & 7.4 \\
Cycle 4 & 5.8 & 5.5 & 4.7 \\
Cycle 5 & 3.61 & 6 & 4.9 \\
Cycle 6 & 2.39 & 4.3 & 3.3
\end{tabular}

cycles, the residual oil production with different pore sizes and its contribution to enhancing oil recovery can be obtained. Fig. 16 shows that there are two wave crests in the three core samples. The two wave crests in the spectrum of Core \#1 indicate that the pores in Core \#1 mainly consist of two sizes of pores. The crest on the left represents micropores and small pores, and the crest on the right represents relatively large pores. The higher the permeability, the larger the amplitude of right wave crest and the larger proportion of larger pore size. The spectrum of Core \#2 has two crests, but there is little transition between the two crests. Moreover, the second wave crest is distributed around $\mathrm{T} 2$ relaxation time equals 100, indicating that right wave crest represents macropores which are fractures. The matrix of Core $\# 2$ was relatively homogeneous, with $\mathrm{T} 2$ relaxation time ranging from 0.1 to 2 . Core \#3 is also homogeneous with most of the oil is distributed on the left wave crest. While the amplitude of the right wave crest is small, indicating that the core is mainly composed of micro pores, with a few mesopores and macropores.

During the $\mathrm{CO}_{2} \mathrm{HnP}$ production, the distribution curve T2 spectrum gradually moves downward to the left, indicating that crude oil in the large pores comes out first, which is consistent with the study by Ma et al. (2019). The oil recovered in the first cycle was dominated by macropores and mesopores, followed by small pores. With the increase of the number of cycles, most of the removable oil in macropores and mesopores has been produced, the oil in small pores and micropores become the main oil-producing area.

\section{Conclusions}

In this study, the interaction of $\mathrm{CO}_{2}$ and formation oil was discussed, and a series of experiments were conducted on the improvement of shale oil production by $\mathrm{CO}_{2} \mathrm{HnP}$ injection. Here, we summarize the main conclusions based on the experimental results.

(1) The purpose of $\mathrm{CO}_{2} \mathrm{HnP}$ is to keep the reservoir pressure high and influences the oil/gas phase equilibrium in the reservoir. The interactions of $\mathrm{CO}_{2}$ and formation crude oil include oil viscosity decline, oil swelling, saturation pressure and critical pressure increasing, which are all beneficial to shale oil production. 


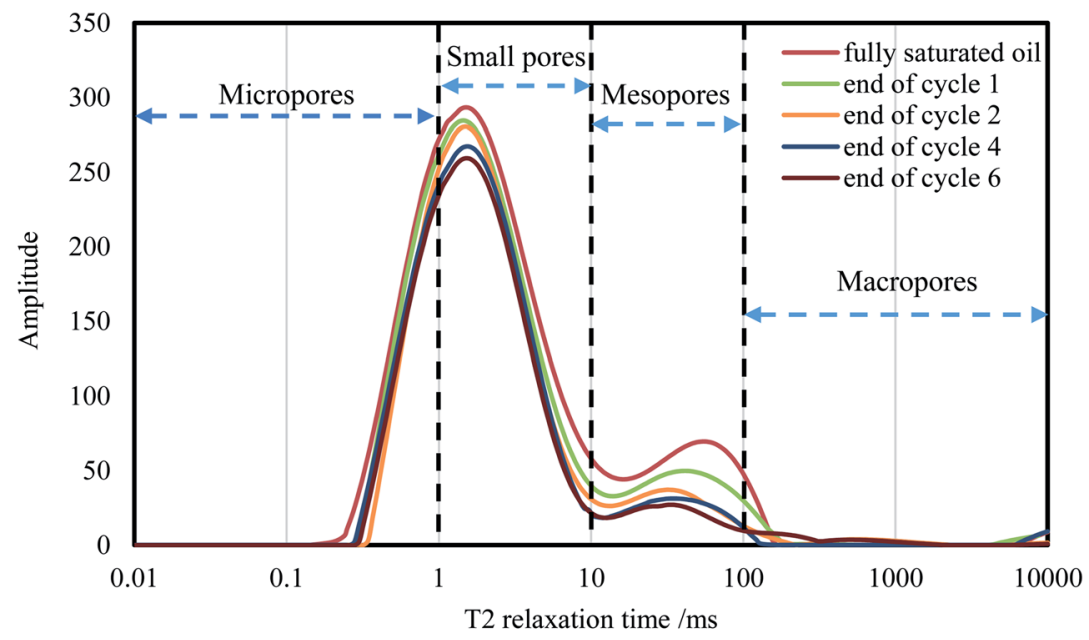

(a) Core \#1

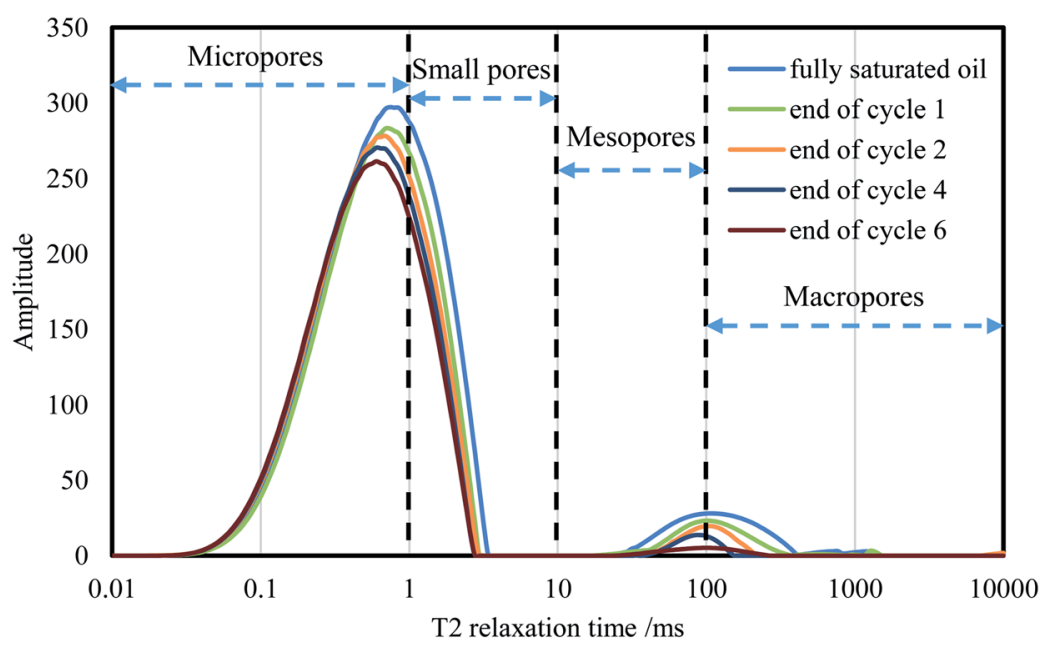

(b) Core \#2

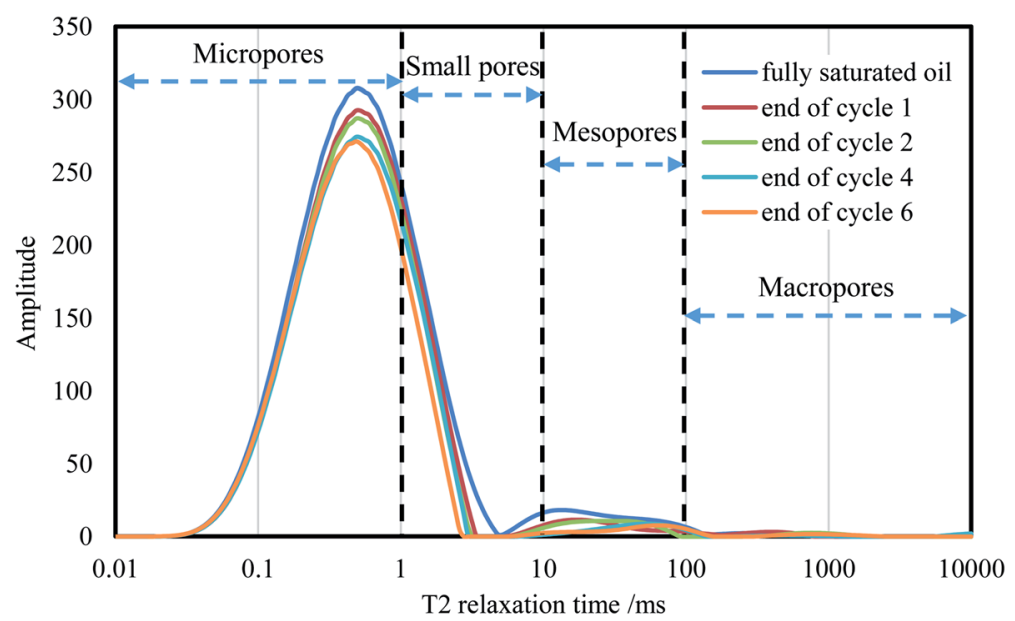

(c) Core \#3

Fig. 16 NMR T2 spectrum curve of remaining oil distribution after different cycle.

(2) The parameters affecting $\mathrm{CO}_{2} \mathrm{HnP}$ EOR performance include reservoir properties such as matrix permeability, induced fractures, and operation parameters such as injection pressure, soaking time, and miscible condition. The influences cannot be determined by one parameter, but needed to synthetically consider other factors together. In general, 
fracture is the fundamental factor affecting oil recovery as it connects oil and gas seepage channels and improves oil and gas percolate capacity. The injection pressure significantly affects the formation oil and gas displacement conditions including miscible or immiscible states. Soaking time is also influenced by injection pressure in the way that longer soaking time is needed when the injection pressure is low or under immiscible condition. However, the advantages of long soaking time will gradually lose at relatively high pressure. The oil recovery factor increases significantly when the operating conditions vary from immiscible to miscible condition. Upon the discussion in this paper, it is of great significant to determine the operating parameters to achieve a good $\mathrm{CO}_{2} \mathrm{HnP}$ EOR performance.

(3) The NMR tests show that the oil production process is dominated by the pore size distribution. The oil in the macropores and mesopores was produced firstly, followed by small pores and micropores. The oil in small pores and micropores become the main oil-producing area in the long term development of shale oil reservoirs.

\section{Conflicts of interest}

There are no conflicts to declare.

\section{Acknowledgements}

The work is supported by the Province Natural Science Foundation of Shandong (ZR2018BEE018), the National Natural Science Foundation of China (51904324, 51974348), China Postdoctoral Science Foundation (2018M630813, 2019T120616), the Fundamental Research Funds for the Central Universities (18CX02170A), the Postdoctoral Applied Research Project Foundation of Qingdao city (BY201802003), and the Funding for Scientific Research of China University of Petroleum East China (YJ20170013).

\section{References}

1 X. Tong, G. Zhang, Z. Wang, Z. Wen, Z. Tian, H. Wang, F. Ma and $\mathrm{Y} . \mathrm{Wu}$, Distribution and potential of global oil and gas resources, Petrol. Explor. Dev., 2018, 45(04), 219-229.

2 M. M. Xue, G. Wu, Q. Wang, et al., Socioeconomic impacts of a shortage in imported oil supply: case of China, Natural Hazards, 2018, 1-16.

3 C. Peter, N. J. Felipe, T. Lanardonne, et al., Across the universe of shale resources - a comparative assessment of the emerging legal foundations for unconventional energy, The Journal of World Energy Law \& Business, 2018, 11(4), 283-321.

4 American Association of Petroleum Geologists, Energy Minerals Division, Unconventional Energy Resources: 2017 Review, Nat. Resour. Res., 2019, 28(4), 1661-1751.

5 B. Jia, J. S. Tsau and R. Barati, A review of the current progress of $\mathrm{CO}_{2}$ injection EOR and carbon storage in shale oil reservoirs, Fuel, 2019, 236, 404-427.

6 L. Li, J. J. Sheng, Y. Su, et al., Further investigation of effects of injection pressure and imbibition water on $\mathrm{CO}_{2}$ huff-n- puff performance in liquid-rich shale reservoirs, Energy Fuels, 2018, 32(5), 5789-5798.

7 L. Jin, S. Hawthorne, J. Sorensen, et al., Advancing $\mathrm{CO}_{2}$ enhanced oil recovery and storage in unconventional oil play-experimental studies on Bakken shales, Appl. Energy, 2017, 208, 171-183.

$8 \mathrm{~T}$. Wan and $\mathrm{Z}$. $\mathrm{Mu}$, The use of numerical simulation to investigate the enhanced Eagle Ford shale gas condensate well recovery using cyclic $\mathrm{CO}_{2}$ injection method with nanopore effect, Fuel, 2018, 233, 123-132.

9 R. Simon and D. J. Graue, Generalized correlations for predicting solubility, swelling and viscosity behavior of $\mathrm{CO}_{2}$-crude oil systems, J. Pet. Technol., 1965, 17(1), 102-106.

10 J. J. Dooley, R. T. Dahowski and C. L. Davidson, The potential for increased atmospheric $\mathrm{CO}_{2}$ emissions and accelerated consumption of deep geologic $\mathrm{CO}_{2}$ storage resources resulting from the large-scale deployment of a ccs-enabled unconventional fossil fuels industry in the U.S, Int. J. Greenhouse Gas Control, 2009, 3(6), 720-730.

11 E. M. Winter and P. D. Bergman, Availability of depleted oil and gas reservoirs for disposal of carbon dioxide in the United States, Energy Convers. Manage., 1993, 34(9-11), 1177-1187.

12 J. W. Choi, J. P. Nicot, S. A. Hosseini, et al., $\mathrm{CO}_{2}$ recycling accounting and EOR operation scheduling to assist in storage capacity assessment at a U.S. gulf coast depleted reservoir, Int. J. Greenhouse Gas Control, 2013, 18, 474-484.

13 B. Iraji, S. R. Shadizadeh and M. Riazi, Experimental investigation of $\mathrm{CO}_{2}$ huff and puff in a matrix-fracture system, Fuel, 2015, 158, 105-112.

14 C. Song and D. Yang, Experimental and numerical evaluation of $\mathrm{CO}_{2}$ huff-n-puff processes in Bakken formation, Fuel, 2017, 190, 145-162.

15 S. Sharma, J. J. Sheng and Z. Shen, A comparative experimental study of huff-n-puff gas injection and surfactant treatment in shale gas-condensate cores, Energy Fuels, 2018, 32(9), 9121-9131.

16 J. Ma, X. Wang, R. Gao, et al., Enhanced light oil recovery from tight formations through $\mathrm{CO}_{2}$ huff 'n'puff processes, Fuel, 2015, 154, 35-44.

17 R. Sun, W. Yu, F. Xu, et al., Compositional simulation of $\mathrm{CO}_{2}$ huff-n-puff process in middle bBakken tight oil reservoirs with hydraulic fractures, Fuel, 2019, 236, 1446-1457.

18 M. Tang, H. Zhao, H. Ma, et al., Study on $\mathrm{CO}_{2}$ huff-n-puff of horizontal wells in continental tight oil reservoirs, Fuel, 2017, 188, 140-154.

19 X. Zhou, Q. Yuan, X. Peng, et al., A critical review of the $\mathrm{CO}_{2}$ huff 'n'puff process for enhanced heavy oil recovery, Fuel, 2018, 215, 813-824.

20 G. Lv, L. Qi, S. Wang and X. Li, Key techniques of reservoir engineering and injection-production process for $\mathrm{CO}_{2}$ flooding in China's sinopec shengli oilfield, $\mathrm{J} . \mathrm{CO}_{2}$ Util., 2015, 11, 31-40.

$21 \mathrm{H}$. Ziguo, Integrated techniques of underground $\mathrm{CO}_{2}$ storage and flooding put into commercial application in the jilin oilfield, China, Acta Geol. Sin., 2012, (1), 285. 
22 C. Bardon, P. Corlay, D. Longeron, et al., $\mathrm{CO}_{2}$ huff-n-puff revives shallow light-oil-depleted reservoirs, SPE Reservoir Eng., 1994, 9(2), 92-100.

23 J. Thomas, T. V. Berzins, T. G. Monger, et al., Light oil recovery from cyclic $\mathrm{CO}_{2}$ injection: influence of gravity segregation and remaining oil, SPE Annu. Tech. Conf. Exhib., 1990, SPE-20531-MS.

24 B. J. Miller, C. P. Bardon and P. Corlay, $\mathrm{CO}_{2}$ huff 'n' puff field case: five-year program update, SPE Permian Basin Oil Gas Recovery Conf., 1994, SPE-27677-MS.

25 F. Torabi and K. Asghari, Effect of operating pressure, matrix permeability and connate water saturation on performance of $\mathrm{CO}_{2}$ huff-and-puff process in matrix-fracture experimental model, Fuel, 2010, 89, 2985-2090.

26 L. Li, Y. Zhang and J. J. Sheng, Effect of the Injection Pressure on Enhancing Oil Recovery in Shale Cores during the $\mathrm{CO}_{2}$ Huff-n-Puff Process When It Is above and below the Minimum Miscibility Pressure, Energy Fuels, 2017, 31(4), 3856-3867.

27 K. Zhang, Experimental and numerical investigation of oil recovery from Bakken formation by miscible $\mathrm{CO}_{2}$ injection, SPE Annu. Tech. Conf. Exhib., 2016, SPE-184486-STU.

28 Y. Zhang, W. Yu, Z. Li, et al., Simulation study of factors affecting $\mathrm{CO}_{2}$ huff-n-puff process in tight oil reservoirs, $J$. Pet. Sci. Eng., 2018, 163, 264-269.

29 C. Song \& D. Yang, Performance evaluation of $\mathrm{CO}_{2}$ huff-npuff processes in tight oil formations, SPE Unconventional Resources Conference Canada, Calgary, Alberta, 5-7 Nov 2013.

30 T. D. Gamadi, J. J. Sheng, M. Y. Soliman; et al., An experimental study of cyclic $\mathrm{CO}_{2}$ injection to improve shale oil recovery, SPE Improved Oil Recovery Symposium, Tulsa, Oklahoma, USA, 12-16 April 2014.

$31 \mathrm{~L}$. Li and J. ,J. Sheng, Numerical analysis of cyclic $\mathrm{CH}_{4}$ injection in liquid-rich shale reservoirs based on the experiments using different-diameter shale cores and crude oil, J. Nat. Gas Sci. Eng., 2017, 39, 1-14.

32 Y. Yu, L. Li and J. J. Sheng, Further discuss the roles of soaking time and pressure depletion rate in gas huff-n-puff process in fractured liquid-rich shale reservoirs, SPE Annu. Tech. Conf. Exhib., 2016.
33 L. Li, Y. Su, Y. Hao, et al., A comparative study of $\mathrm{CO}_{2}$ and $\mathrm{N}_{2}$ huff-n-puff EOR performance in shale oil production, J. Pet. Sci. Eng., 2019, 181, 106174.

$34 \mathrm{H}$. H. Hsu and R. J. Brugman, $\mathrm{CO}_{2}$ huff-puff simulation using a compositional reservoir simulator, SPE Annu. Tech. Conf. Exhib., 1986.

35 B. T. Hoffman, Comparison of various gases for enhanced recovery from shale oil reservoirs. SPE Improved Oil Recovery Symposium, Tulsa, Oklahoma, 14-18 April 2012.

$36 \mathrm{~W}$. $\mathrm{Yu}, \mathrm{H}$. R. Lashgari, K. Wu and K. Sepehrnoori, $\mathrm{CO}_{2}$ injection for enhanced oil recovery in Bakken tight oil reservoirs, Fuel, 2015, 159, 354-363.

37 Z. Meng, S. Yang, L. Wang, et al., Investigation on numerical simulation of $\mathrm{CO}_{2}$ huff and puff in tight oil reservoirs, $J$. of Petrochem. Univ., 2016, 29(6), 39-42.

38 J. Sun, A. Zou, E. Sotelo, et al., Numerical simulation of $\mathrm{CO}_{2}$ huff-n-puff in complex fracture networks of unconventional liquid reservoirs[J], J. Nat. Gas Sci. Eng., 2016, 31, 481-492.

39 P. Zuloagamolero, W. Yu, Y. Xu, et al., Simulation Study of $\mathrm{CO}_{2}$-EOR in tight oil reservoirs with complex fracture geometries, Sci. Rep., 2016, 6, 33445.

$40 \mathrm{Z}$. Yuan, Y. Wei, Z. Li, et al. Simulation study of factors affecting $\mathrm{CO}_{2}$ huff-n-puff process in tight oil reservoirs, $J$. Pet. Sci. Eng., 2018, 163, 264-269.

41 L. Sheng and L. Peng, Experimental and simulation determination of minimum miscibility pressure for a Bakken tight oil and different injection gases, Petroleum, 2017, 3(1), 79-86.

42 J. J. Sheng, Critical review of field EOR projects in shale and tight reservoirs, J. Pet. Sci. Eng., 2017, 159, 654-665.

43 Zh. Li, Y. Sun, R. Hu, et al., Quantitative analysis for nanopore structure characteristics of shales using NMR and NMR cryoporometry, J. Eng. Geol., 2018, 26(3), 758-766.

44 Q. Ma, Sh. Yang, D. Lv, et al., Experimental investigation on the influence factors and oil production distribution in different pore sizes during $\mathrm{CO}_{2}$ huff-n-puff in an ultrahigh-pressure tight oil reservoir, J. Pet. Sci. Eng., 2019, 178, 1155-1163.

45 K. S. Pedersen \& P. L. Christensen, Phase behavior of petroleum reservoir fluids, CRC Press, 2007. 